\title{
AKTIVITAS PEMBERIAN KREDIT KONSUMTIF PADA PT. PEGADAIAN SYARIAH UNIT SITEBA
}

\author{
Yulia Syafputri, Mariani St.B Tanjung \\ Akademi Keuangan dan Perbankan Padang \\ mstbtanjung@gmail.com
}

\begin{abstract}
Pegadaian Syariah as a distributor and service provider of credit mainly on credit consumptive with a warranty to the public especially, to the public the lower middle class are still many do not know about the activity of granting consumer credit in the . Pegadaian Syariah and the guarantee of what is proposed in the provision of credit services. The purpose of this study is to determine how the activity of granting consumer credit at PT. Pegadaian Syariah Siteba Unit. With the research methods of literature study and field is by interview. The results of the study can be concluded that the activity of granting consumer credit services at PT. Pegadaian Syariah Unit Siteba very well this is indicated on the increase from year to year.
\end{abstract}

Keywords: administration activities, consumptive

\section{LATAR BELAKANG}

Dalam menjalankan kegiatan perekonomian, uang ikut berperan penting di dalamnya. Karena uang merupakan alat tukar pembayaran yang di sahkan untuk memenuhi kebutuhan perekonomian masyarakat. terkadang kebutuhan akan uang tunai menjadi kebutuhan yang segera pada waktu - waktu tertentu. Kebutuhan akan uang tunai tersebut di perlukan dengan berbagai alasan seperti, kebutuhan primer yang di gunakan masyarakat sebagai kebutuhan pokok yang harus wajib di miliki. Namun demikian, kebutuhan - kebutuhan tersebut adakalanya tidak diimbangi dengan ketersediaan uang tunai yang dimiliki. namun untuk kebutuhan yang sangat penting terpaksa harus dipenuhi dengan berbagai cara seperti meminjam dari berbagai sumber pembiayaan yang ada.

Diantara berbagai sumber pembiayaan dana yang ada tersebut yaitu lembaga keuangan. lembaga keuangan adalah suatu badan yang bergerak di bidang keuangan untuk menyediakan jasa bagi nasabah atau masyarakat. Lembaga Keuangan ini juga terbagi dalam berbagai jenis. Yaitu Lembaga Keuangan Bank yang terdiri dari Bank Sentral, Bank Umum, dan Bank 
Perkreditan Rakyat ( BPR ) . dan lembaga keuangan bukan bank. Salah satu lembaga keuangan bukan bank tersebut yaitu PT. Pegadaian Syariah.

PT. Pegadaian Syariah adalah suatu lembaga keuangan non perbankan yang memberikan jasa kredit kepada masyarakat yang jasanya berorientasi pada jaminan. PT. Pegadaian Syariah merupakan salah satu lembaga formal di Indonesia yang berdasarkan hukum diperbolehkan melakukan pembiayaan dengan bentuk penyaluran kredit atas dasar hukum gadai.

Kegiatan yang dilakukan oleh PT. Pegadaian Syariah adalah Pertama melakukan aktivitas pembiayaan, aktivitas pembiayaannya melalui penyaluran dana yang berasal dari modal perusahaan atau dana-dana yang berhasil dihimpun oleh PT. Pegadaian Syariah. Kedua menawarkan produk berupa sejumlah jasa non gadai (Arthesa dan Handiman, 2006: 272 ) .

Berdasarkan latar belakang masalah diatas maka rumusan masalah dalam penelitian ini adalah bagaimana aktivitas pemberian kredit konsumtif pada PT. Pegadaian Syariah Unit Siteba.

\section{TINJAUAN PUSTAKA}

\section{Pengertian Pegadaian}

Pegadaian adalah suatu lembaga keuangan non perbankan yang memberikan jasa kredit kepada masyarakat yang jasanya berorientasi pada jaminan. Menurut hukum gadai, calon peminjam mempunyai kewajiban untuk menyerahkan harta yang di punyai nya sebagai jaminan kepada pihak Pegadaian. Dalam hukum tersebut juga memuat suatu pembelian hak kepada pegadaian untuk melakukan penjualan atau lelang atas jaminan tersebut jika batas waktu tempo pinjaman yang telah di tentukan telah habis dan peminjam belum juga menebus jaminannya.

\section{Jenis - Jenis Pegadaian}

a. Pegadaian Konvensional

Merupakan suatu lembaga pemerintah yang memberikan uang pinjaman terhadap nasabah atas dasar hukum gadai. Pegadaian konvensional ini sudah tersebar ke seluruh wilayah termasuk pedesaan. Namun pegadaian konvensional ini masih menggunakan sistem pencatatan manual, dengan menggunakan sistem bunga dan tarif jasa simpanannya yang cukup besar yaitu maksimum $1,15 \%$ ( dari uang pinjaman ).

b. Pegadaian Syariah

Merupakan suatu lembaga keuangan atau devisi dari bentuk Pegadaian dengan memberikan uang pinjaman sesuai dengan prinsip - prinsip syariat islam.

\section{Pengertian Kredit}

Kata kredit secara etymologi berasal dari bahasa yunani yaitu " credere" yang berarti kepercayaan. Kepercayaan di lihat dari sisi bank adalah suatu keyakinan bahwa uang yang di berikan akan dapat di kembalikan tepat pada waktunya sesuai Menurut Drs. Muchdarsyah Sinungan pengertian kredit adalah suatu pemberian prestasi oleh suatu pihak kepada pihak lain dan prestasi itu akan di kembalikan lagi pada suatu masa tertentuyang akan datang di sertai dengan contra prestasi berupa bunga. (Suharno, 2003 : 1). 
sedangkan pengertian kredit menurut Undang - Undang Perbankan nomor 10 tahun 1998 adalah penyediaan uang atau tagihan yang dapat di persamakan dengan itu berdasarkan persetujuan atau kesepakatan pinjam meminjam antara bank dengan pihak lain yang mewajibkan pihak peminjam melunasi utangnya setelah jangka waktu tertentu dengan pemberian bunga. ( dalam Manajemen Perbankan, 2004 : 73 ) .

dengan kesepakatan kedua belah pihak yang tertuang dalam akte perjanjian kredit. Dari pengertian diatas dapat di simpulkan bahwa kredit merupakan kesepakatan kedua belah pihak untuk saling memberi dan menerima sesuatu dimana pada saat tertentu pihak penerima harus membayar pokok dan ganti rugi ( Opportunity Cost ) atas dana yang di pinjamnya. Besarnya ganti rugi ( bunga ) dan syarat - syarat penarikan dan atau pembayaran biasanya di tuangkan dalam bentuk akte perjanjian kredit. ( Suharno, 2003:1 ).

\section{Unsur - Unsur Kredit}

\section{a. Kepercayaan}

yaitu suatu keyakinan pemberi kredit ( bank ) bahwa kredit yang di berikan akan benar - benar di terima kembali di masa mendatang sesuai dalam jangka waktu kredit.

b. Kesepakatan

Mengandung kesepakatan antara si pemberi kredit dengan si penerima kredit yang di tuangkan dalam suatu perjanjian.

c. Jangka Waktu

Jangka waktu ini mencakup masa pengembalian kredit yang telah di sepakati.

d. Resiko

Dapat diakibatkan dua hal yaitu resiko kerugian yang di akibatkan nasabah sengaja tidak mau membayar kreditnya dan akibat terjadinya musibah.

e.Balas Jasa

Akibat dari pemberian fasilitas kredit di harapkan mendapat keuntungan berupa bunga.

\section{Tujuan dan Fungsi Kredit}

\section{Tujuan Kredit}

1) Mendapatkan pendapatan bank pada hasil bunga yang di terima.

2) Memproduktifkan dan memanfaatkan dana - dana yang ada.

3) Menjalankan pada kegiatan operasional bank.

4) Menambah modal kerja di perusahaan.

5) Mempercepat lalu lintas pembayaran.

6) Meningkatkan kesejahteraan dan pendapatan dari masyarakat.

\section{Fungsi Kredit}

1) Meningkatkan Daya Guna Uang

2) Meningkatkan Daya Guna Barang

3) Meningkatkan Kecepatan Peredaran dan Lalu Lintas Uang

4) Meningkatkan Kegairahan Berusaha

5) Meningkatkan Daya Beli

6) Mempelancar Kegiatan Perdagangan

7) Menjalin Hubungan Internasional 
8) Sebagai alat Kebijakan Moneter

\section{Jenis - Jenis Kredit}

Rahcmat Firdaus dan Maya Ariyanti ( 2003 : 10 ) mengemukakan macam- macam kredit :

a. Kredit menurut tujuan dan penggunaannya

1) Kredit Konsumtif, yaitu Kredit yang di gunakan untuk membiayai pembelian barang - barang atau jasa - jasa yang dapat memberikan kepuasan langsung terhadap kebutuhan manusia.

2) Kredit Produktif, yaitu kredit yang di gunakan untuk tujuan produktif dalam arti dapat menimbulkan atau meningkatkan faedah atau kegunaan, baik faedah karena bentuk, faedah karena tempat atau faedah karena tempat umum.

b. Menurut Jangka waktunya

1) Kredit Jangka Pendek

Kredit yang berjangka satu tahun.

2) Kredit Jangka Menengah

Kredit yang jangka waktunya antara 1 tahun sampai 3 tahun.

3) Kredit Jangka Panjang

Kredit yang berjangka waktu lebih dari 3 tahun. Kredit macam ini biasanya lebih cocok untuk kredit investasi seperti pembelian mesin berat.

c. Kredit di Tinjau dari Segi Materi

1) Kredit dalam bentuk uang

Pada umumnya di berikan dalam bentuk uang dan pengembaliannya pun dalam bentuk uang juga.

2) Kredit dalam bentuk bukan uang

Kredit demikian berupa benda - benda atau jasa yang biasanya di berikan oleh perusahaan - perusahaan dagang dan sebagainya.

\section{Pengertian Jaminan}

Jaminan menurut Hartono Hadisoeprapto ( 1984 : 50 ) adalah sesuatu yang di berikan kepada kreditur untuk menimbulkan keyakinan bahwa debitur akan memenuhi kewajiban yang dapat di nilai dengan uang yang timbul dari suatu perikatan.

\section{Jenis - Jenis Jaminan}

a. Jaminan Kebendaan

Adalah penyerahan hak oleh debitur atau pihak ketiga atas barang - barang miliknya kepada bank guna di jadikan agunan atas kredit yang di peroleh debitur.

\section{Peranan jaminan}

a. untuk memberikan hak dan kekuasaan kepada pihak bank untuk mendapatkan pelunasan dengan barang - barang agunan tersebut. Bila nasabah bercedera janji, yaitu tidak bisa membayar kembali utangnya pada waktu yang telah di tetapkan dalam perjanjian.

b. Menjamin agar nasabah berperan dan atau turut serta dalam transaksi yang di biayai sehingga kemungkinan nasabah untuk meninggalkan usaha atau proyek dengan merugikan diri sendiri atau persahaannya dapat di cegah, atau minimum kemungkinan untuk berbuat demikian di perkecil. 
c. memberi dorongan kepada debitur untuk memenuhi perjanjian kredit khususnya mengenai pembayaran kembali ( pelunasan ) sesuai dengan syarat - syarat yang telah di setujui agar debitur tidak kehilangan kekayaan yang telah di jaminkan kepada bank.

\section{Analisa dan Pembahasan}

Prosedur Pemberian Kredit Konsumtif Pada PT. Pegadaian Syariah Unit Syariah Unit Siteba dimulai dari 1) penyerahan barang jaminan. 2). Mengisi formulir permintaan kredit. 3) proses penaksiran barang jaminan.

Untuk melihat perkembangan pemakaian jasa kredit pada PT. Pegadaian Syariah Unit Siteba dari tahun ke tahun dapat di lihat pada tabel dibawah ini:

Tabel Perkembangan Pemakaian Jasa Kredit

PT. Pegadaian Syariah Unit Siteba

Tahun 2013 - 2016

\begin{tabular}{|c|c|c|}
\hline \multirow{2}{*}{ Tahun } & \multicolumn{2}{|c|}{ Kredit } \\
\cline { 2 - 3 } & $\begin{array}{c}\text { Jumlah } \\
(\mathbf{R p})\end{array}$ & $\begin{array}{c}\text { Perubahan } \\
(\mathbf{R p})\end{array}$ \\
\hline 2013 & 12.220 .140 & - \\
\hline 2014 & 13.019 .340 & 0,06 \\
\hline 2015 & 17.552 .170 & 0,34 \\
\hline 2016 & 18.854 .890 & 0,07 \\
\hline
\end{tabular}

Sumber : PT. Pegadaian Syariah Unit Siteba 
Berdasarkan tabel 3.1 pemakaian jasa kredit pada PT. Pegadaian Syariah Unit Siteba dari tahun 2013 sampai tahun 2016 pemakaian jasa kredit cenderung meningkat pada tahun 2013 - 2014 sebesar Rp. 799.240,- atau sebesar $0.06 \%$. begitu juga pada tahun 2014 - 2015 sebesar Rp. 4.532. 830,atau sebesar 0,34 \% . kemudian pada tahun 2015 - 2016 sebesar Rp. 1.302.720 atau sebesar $0,07 \%$. hal ini di sebabkan karena banyak nya minat masyarakat, terutama pada masyarakat di sekitar wilayah siteba dalam melakukan kredit secara gadai dengan jaminan emas, kendaraan, dan lain sebagainya. Perkembangan ini di harapkan dapat meningkat pada tahun selanjutnya, Mengingat proses pemberian kredit pada PT. Pegadaian Syariah Unit Siteba ini mudah, cepat, aman dan tentunya tidak membutuhkan proses yang lama.

\section{KESIMPULAN DAN SARAN \\ Kesimpulan}

Berdasarkan pengamatan tentang aktivitas pemakaian jasa kredit konsumtif pada PT. Pegadaian Syariah Unit Siteba dapat di ambil kesimpulan bahwa aktifitas pemberian kredit konsumtif pada PT. Pegadaian Syariah ini di mulai dari proses penyerahan barang jaminan, mengisi formulir permintaan kredit dan syarat pengajuan kredit gadai ( Rahn ) yaitu dengan menyerahkan kartu indentitas diri, seperti KTP, SIM dan lainnya oleh calon nasabah kepada petugas penaksir. Kemudian petugas penaksir akan menaksir barang calon nasabah yang nantinya akan di jadikan sebagai barang jaminan guna memperoleh kredit gadai, setelah barang jaminan di periksa dan di taksir oleh petugas penaksir. Kemudian pihak pengelola akan membuatkan Surat Bukti Kredit ( SBK ) atas nama pemohon kredit sesuai dengan indentitas yang tertera dalam fotocopy indentitas diri. Setelah selesai maka petugas penaksir akan menyerahkan kepada petugas kasir. Kasir akan melakukan pengecekan terhadap besarnya uang pinjaman.

\section{Saran}

1. Sebaiknya PT. Pegadaian Syariah Unit Siteba lebih banyak lagi melakukan kegiatan promosi baik itu di wilayah sekitar siteba maupun di wilayah lainnya serta menjelaskan kepada masyarakat terutama masyarakat golongan menengah ke bawah agar masyarakat mengetahui apa - apa saja produk yang di miliki oleh Pegadaian Syariah dan apa - apa saja keuntungan yang di peroleh serta menjelaskan kepada masyarakat terutama masyarakat golongan menengah ke bawah.

2. Sebaiknya PT. Pegadaian Syariah Unit Siteba menjelaskan kepada masyarakat bagaimana aktivitas pemberian jasa kredit kepada masyarakat sekitar wilayah siteba agar masyarakat memahaminya.

3. PT. Pegadaian Syariah Unit Siteba seharusnya memasang papan iklan yang berisi tentang produk - produk kredit dan apa - apa saja barang jaminan yang dapat di gadaikan di PT. Pegadaian Syariah tersebut. 


\section{DAFTAR PUSTAKA}

Ade Arthesa dan Edia Handiman, 2006. Bank dan Lembaga Keuangan Bukan Bank. Jakarta : PT. Indeks

Alanshari, F., \& Marlius, D. (2018). Prosedur Pemberian Kredit KPR Pada PT. Bank Tabungan Negara (Persero) TBK Cabang Pembantu Bukittinggi. https://doi.org/10.31227/osf.io/rsfhc

Amelia, L., \& Marlius, D. (2018). Pengendalian Kredit Dalam Upaya Menciptakan Bank Yang Sehat Pada PT. Bank Pembangunan Daerah Sumatera Barat Cabang Utama Padang. https://doi.org/10.31227/osf.io/kpc64

Andriani, B., \& Susanto, R. (2019). Pengawasan Kredit PT. Bank Perkreditan Rakyat (BPR) Ophir Pasaman Barat. https://doi.org/10.31219/osf.io/aunvc

Baiya, \& Fernos, J. (2019). Analisis Faktor-Faktor Penyebab Kredit Macet Pada Bank Nagari Cabang Siteba. https://doi.org/10.31227/osf.io/4xuks

Darmawanto, \& Fernos, J. (2019). Prosedur Pemberian Kredit Pada Bank Nagari Cabang Sijunjung. https://doi.org/10.31227/osf.io/psqfy

Firmansyah, A., \& Fernos, J. (2019). Analisis Kredit Bermasalah Dilihat Dari Standar Non Performing Loan (NPL) Pada PT. Bank Perkreditan Rakyat (BPR) Prima Mulia Anugrah Cabang Padang. https://doi.org/10.31227/osf.io/gcj94

Gibson James L, 1997. Organisasi dan Struktur Organisasi, Penerbit Erlangga, ( edisi ke-2)

Ikbal, M., \& Marlius, D. (2017). Pengaruh Jumlah Taksiran Dan Uang Pinjaman Terhadap Laba Bersih Pada PT. Pegadaian (UPC) Gurun Laweh. https://doi.org/10.31227/osf.io/uch4a

Kuncoro, Mudrajad dan Suhardjono.2002. Manajemen Perbankan. Yogyakarta: BPFE.

Orlando, A., \& Susanto, R. (2019). Mekanisme Pencairan Kredit Usaha Rakyat Pada PT. Bank Rakyat Indonesia Unit Lubuk Buaya. https://doi.org/10.31219/osf.io/zuv2y

Satrio, J, 1993. Hukum Jaminan, Hak - Hak Jaminan Kebendaan, Bandung : Citra Aditya Bakti 
Suyatno, Thomas. 2000. Dasar-Dasar Perkreditan. Jakarta: PT. Gramedia Pustaka Utama.

Undang - Undang RI No. 10 Tahun 1998 tentangPerbankan Undang-Undang No. 7 Tahun 1992 Tentang Perbankan. 2002. Jakarta: PT. Sinar Grafika.

Triandaru, Sigit dan totok Budisantoso. 2006. Bank dan Lembaga Keuangan Lain ( edisi ke-2 ). Jakarta: Salemba empat

Widayati, R. (2019). Penyelesaian Kredit Bermasalah Pada PT. Bank Perkreditan Rakyat (BPR) Nagari Kasang. https://doi.org/10.17605/OSF.IO/D4MF3

Widayati, R. (2019). Pelaksanaan Prinsip Kehati-Hatian Dalam Pemberian Kredit Konsumtif Pada Bank Nagari Cabang Siteba. https://doi.org/10.17605/OSF.IO/FZVXR

Widayati, R. (2019). Aktivitas Pemberian Kredit Komersil Pada Bank Nagari Cabang Sijunjung. https://doi.org/10.17605/OSF.IO/QTVZ9

Widayati, R. (2019). Pelaksanaan Kredit Pada Bank Perkreditan Rakyat LPN Pasar Baru Durian Sawahlunto. https://doi.org/10.17605/OSF.IO/5HPAB

Widayati, R. (2019). Upaya Penanganan Kredit Bermasalah Pada Bank Nagari Cabang Utama Padang. https://doi.org/10.17605/OSF.IO/YJ3KN

Widayati, R. (2019). Aktivitas Pemberian Kredit Usaha Pada PT. Bank Perkreditan Rakyat Batang Kapas. https://doi.org/10.17605/OSF.IO/EDPN4 